\title{
Thermally reversible cross-linked poly(ether-urethane)s
}

\author{
C. Gaina, O. Ursache, V. Gaina*, C. D. Varganici \\ 'Petru Poni’ Institute of Macromolecular Chemistry, 41 A Gr.Ghica Voda Alley, RO-700487 Iasi, Romania
}

Received 6 February 2013; accepted in revised form 14 April 2013

\begin{abstract}
Cross-linked poly(ether-urethane)s were prepared by Diels-Alder (DA) reaction of the furan-containing poly(ether-urethane) to bismaleimides and showed thermal reversibility evidenced by differential scanning calorimetry and attenuated total reflectance in conjunction with Fourier transform infrared spectroscopy (ATR-FTIR). The furan-containing poly(ether-urethane)s were synthesized by the polyaddition reaction of 1,6-hexamethylene diisocyanate (HMDI) or 4,4'dibenzyl diisocyanate (DBDI) to poly(tetramethylene ether) glycol (PTMEG having $M_{\mathrm{n}}=250,650,1000,1500$ and 2000) and 2-[N,N-bis(2-methyl-2-hydroxyethyl)amino]furfuryl as chain extender by the solution prepolymer method. The molar ratio of isocyanate: PTMEG:chain extender varied from 2:1:1 to 4:1:3, which produces a molar concentration of furyl group ranging between $3.65 \cdot 10^{-4}$ and $1.25 \cdot 10^{-3} \mathrm{~mol} / \mathrm{g}$.
\end{abstract}

Keywords: thermal properties, polyurethanes, Diels-Alder reaction, networks

\section{Introduction}

The application of reversible Diels-Alder (rDA) chemistry to the dynamic covalent assembly of organic materials has been only recently explored [1-4]. The number of DA reactions that undergo dynamically reversible adduct formation under mild conditions is, however, limited and there is an increasing interest in expanding the set of dynamic covalent DA reactions [5-8].

Over the past 10 years several groups have explored the use of reversible DA adduct formation in the design and synthesis of new organic materials, the most of such studies utilize the reactivity of electronrich furan derivatives and electron-poor maleimide derivatives [9]. The DA cycloaddition of furan and maleimide can be accomplished at or slightly above room temperature, while the rDA reaction is performed at elevated temperatures.

Thermally rDA reactions have been used in numerous studies including polymer synthesis [10-17], dendrimers [18-21], epoxy resins [22-25], crosslinked polymer networks [26-30], organic-inor- ganic polymer hybrids [31-33], surfactants [34], surface modification $[35,36]$ and remendable selfhealing polymers [37]. Due to the fact that these reactions can proceed under mild conditions without a catalyst, they are attractive for designing covalently reversible bonds with furan and maleimide functional groups which are responsible for association and disassociation [35, 37, 38].

Polyurethanes are widely used in high resiliency flexible foam seating, rigid foam insulation panels, microcellular foam seals and gaskets, durable elastomeric wheels and tires, automotive suspension bushings, electrical potting components, high performance adhesives, surface coatings and sealants, Spandex fibers, seals, gaskets, carpet underlay, and hard plastic parts (such as for electronic instruments). For the manufacture of polyurethanes, two groups of at least bifunctional substances are needed as reactants: 1) isocyanate groups (diisocyanates, polyisocyanates), and 2) active hydrogen atoms (polyols, glycols, triols etc.). Two side reactions can occur during polyurethane synthesis: formation of

\footnotetext{
${ }^{*}$ Corresponding author, e-mail: vgaina@icmpp.ro

(C) BME-PT
} 
both allophanate and biuret linkages from isocyanate functionality and an already existing urethane link. Both reactions not only affect stoichiometry, but also introduce branching, yielding crosslinked species. Polyurethanes can thus be formed through the branching and cross-linking. Due to these types of cross-links that are typically present in polyurethane, the polyurethane materials become difficult to melt process and difficult to remove once it is potted.

Taking advantage of experimental conditions, we report the formation of poly(ether urethane) networks with reversibly removable properties. Our approach to removable polymer networks is the introduction of chemically labile linkages within cross-linked polymeric networks. We have explored the DA cycloaddition reactions between bismaleimide and furyl monomers or polymers [3942]. The mechanical measurements showed a greater elongation at break for obtained polyurethane networks, elongation which can be even nine times higher than that of previously obtained polyurethane networks by Diels-Alder reaction [41].

\section{Experimental part}

\subsection{Measurements}

The FTIR spectra were recorded on a Bruker Vertex 70 Instruments (Austria) equipped with a Golden Gate single reflection ATR accessory, spectrum range $600-4000 \mathrm{~cm}^{-1}$.

The proton nuclear magnetic resonance ( $\left.{ }^{1} \mathrm{H}-\mathrm{NMR}\right)$ spectra were recorded on a Bruker NMR spectrometer, Avance DRX $400 \mathrm{MHz}$, using $\mathrm{CDCl}_{3}$ and DMSO- $\mathrm{d}_{6}$ as solvent and tetramethylsilane as an internal standard.

Differential scanning calorimetry (DSC) measurements were conducted on a DSC 200 F3 Maia (Netzsch, Germany). About $9 \mathrm{mg}$ of sample were heated in pressed and punched aluminum crucibles at a heating rate of $10^{\circ} \mathrm{C} /$ minute. Nitrogen was used as inert atmosphere at a flow rate of $100 \mathrm{~mL} /$ minute. Thermogravimetric analysis (TGA) was conducted on a STA 449 F1 Jupiter device (Netzsch, Germany). Around $10 \mathrm{mg}$ of each sample was heated in alumina crucibles at a heating rate of $10^{\circ} \mathrm{C} / \mathrm{min}$. Nitrogen was used as inert atmosphere at a flow rate of $50 \mathrm{~mL} / \mathrm{min}$.

The reduced viscosity of polyurethane was measured $\left(c=0.5 \mathrm{~g} / \mathrm{dL}, 25 \pm 0.2^{\circ} \mathrm{C}\right)$ in DMF using an Ubbelohde viscometer.
Gel permeation chromatographic (GPC) analyses were carried out on a PL-EMD 950 Evaporative light Detect instrument using $N, N$-dimethylformamide (DMF) as the eluant and standard polystyrene sample for calibration.

Dynamic contact angles were performed by the Wilhelmy plate technique, using a Sigma 700 precision tensiometer produced by KSV Instruments. The sample plate dimensions were $50 \times 8 \mathrm{~mm}$ and rate of immersion-emersion was $5 \mathrm{~mm} / \mathrm{min}$ in water. Immersion depth was $5 \mathrm{~mm}$ in standard conditions. All measurements were the average of 3 contact angle measurements of samples.

Stress-strain measurements were performed on a test apparatus, Shimadzu AGS-J, cell load 1 kN. Measurements were run at an extension rate of $10 \mathrm{~mm} / \mathrm{min}$, at room temperature $23^{\circ} \mathrm{C}$. All samples were measured three times and the averages were obtained.

\subsection{Reagents and materials}

Dibuthyltin dilaureate (Aldrich, 95\%), dimethylformamide (DMF, Aldrich, 99\%), poly(tetramethylene ether) glycol (PTMEG) (Terathane-250, -650, $-1000,1500$ and -2000) (Aldrich), 2-furfuryl amine (Aldrich), epoxy propane (Aldrich), 1,6-hexamethylene diisocyanate (HDMI) (Aldrich) were used as received. 4,4'-Dibenzyldiisocyanate (DBDI) (Savinesti, Romania) was purified before use by recrystallization from anhydrous cyclohexane ( $\mathrm{mp}=$ 89-90 ${ }^{\circ} \mathrm{C}$ ), 4,4'-bismaleimido-diphenylmethane (A) was synthesized from 4,4'-diaminodiphenylmethane and maleic anhydride in a two-step method described in the literature [43] and recrystallized from toluene $\left(m p=158-159^{\circ} \mathrm{C}\right)$. The oligoether urethane bismaleimide (B) was synthesized from Terathane-650 and 4-maleimidophenyl isocyanate by the method described in the literature [41].

\section{Synthesis of}

2-[N,N-bis(2-methyl-2-hydroxyethyl)amino]furfuryl

This material was prepared according to the modified method described in the literature [44]. To a solution of epoxy propane $(11.6 \mathrm{~g}, 0.2 \mathrm{~mol})$ in toluene $(80 \mathrm{~mL}), 2$-furfuryl amine $(9.3 \mathrm{~g}, 0.1 \mathrm{~mol})$ and acetic acid $(1 \mathrm{~mL})$ were added. The mixture was stirred and refluxed for 3 hours. The solvent was evaporated out using a rotary evaporator. The crude product was washed with $50 \mathrm{~mL}$ cyclohexane three 
times. After drying under vacuum at $50^{\circ} \mathrm{C}$ for 36 hours, a viscous liquid product was obtained.

Analysis calculated for $\mathrm{C}_{11} \mathrm{H}_{19} \mathrm{NO}_{3}(213.273)$ : $\mathrm{C}$, $61.95 ; \mathrm{H}, 8.98 ; \mathrm{N}, 6.56 \%$. Found: C, 62.13; H, 9.02; $\mathrm{N}, 6.48 \%$.

${ }^{1} \mathrm{H}-\mathrm{NMR}\left(\mathrm{CDCl}_{3}\right), \delta(\mathrm{ppm}): 1.12\left(\mathrm{~d}, 6 \mathrm{H}, \mathrm{CH}_{3}\right), 2.38-$ $2.62\left(\mathrm{~m}, 4 \mathrm{H}, \mathrm{CH}_{2}\right.$ protons), $3.58(\mathrm{~s}, 2 \mathrm{H}, \mathrm{OH}$ protons), 3.75 (s, $2 \mathrm{H}, \mathrm{CH}_{2}$ protons), $3.83(\mathrm{~m}, 2 \mathrm{H}, \mathrm{CH}-\mathrm{N}$ protons), 6.18 (s, 1H, 3-furfuryl proton), 6.30 (s, $1 \mathrm{H}, \mathrm{CH}$-furfuryl), 7.37 (s, $1 \mathrm{H}, \mathrm{C}_{5}$ of furan).

\section{Synthesis of poly(ether-urethane)s containing furan ring PU-(1-12)}

The polyurethanes were synthesized by the conventional two-step method under an inert atmosphere of high purity nitrogen in a $100 \mathrm{~mL}$ three-neck round bottomed flask equipped with a stirrer and a thermometer. A $10 \% \mathrm{w} / \mathrm{v}$ solution of poly(tetramethylene ether) glycol (PTMEG) in $N, N^{\prime}$-dimethylformamide (DMF) was mixed with the catalyst, dibutyltin dilaureate (about $0.5 \mathrm{wt} \%$ ) at $40^{\circ} \mathrm{C}$ for 30 minutes to obtain a homogeneous solution. In the first step, an excess of diisocyanate was added to obtain an isocyanate-terminated prepolymer (at several $\mathrm{NCO} / \mathrm{OH}$ ratio of 2,3 and 4 ) and the reaction was left for 2 hours at $80^{\circ} \mathrm{C}$. The prepolymer solution was cooled at $60^{\circ} \mathrm{C}$ and chain extension step was performed adding stoichiometric amount of 2-[ $N, N^{\prime}$-bis(1-methyl-2-hydroxyethyl)amino]furfuryl in $5 \mathrm{~mL}$ DMF under nitrogen and stirring for
2 hours at $60^{\circ} \mathrm{C}$. The solution was cooled $\left(25^{\circ} \mathrm{C}\right)$ and the polymer was precipitated in cool distilled water and washed with methanol at room temperature. The sample was then dried at $50^{\circ} \mathrm{C}$ for 24 hours under reduced pressure. The polyurethane films were cast from $8 \mathrm{wt} \%$ solution of the polymer in DMF.

IR $\left(\mathrm{KBr}, \mathrm{cm}^{-1}\right)$ : 3395, 2968, 2932, 2885, 1833 , 1632, 1502, 1454, 1411, 1375, 1337, 1279, 1147 , $1067,1013,949,838,732$ and 599.

\section{Synthesis of polyurethane networks NPU-(1-12)A,B}

To a solution of polyurethane $(1.2 \mathrm{~g})$ in DMF $(10 \mathrm{~mL})$, a stoichiometric bismaleimide monomer (A or B) was added. The mixture was stirred at $60^{\circ} \mathrm{C}$ for 2 hours and the solution was cast on Teflon Petri dish and the solvent was evaporated at $60^{\circ} \mathrm{C}$ for 24 hours. The obtained polymer films were used for all characterizations. NPU, before crosslinking, were soluble in aprotic dipolar solvents at room temperature. After crosslinking, when the samples were immersed in aprotic dipolar solvents, polyurethane networks swelled. At $140^{\circ} \mathrm{C}$, the networks became soluble as a result of the decrosslinking at this temperature.

\section{Results and discussion}

Polyurethanes containing furan moieties PU-(1-12) were prepared by the two-step method in DMF solution, by the reaction of DBDI or HMDI with

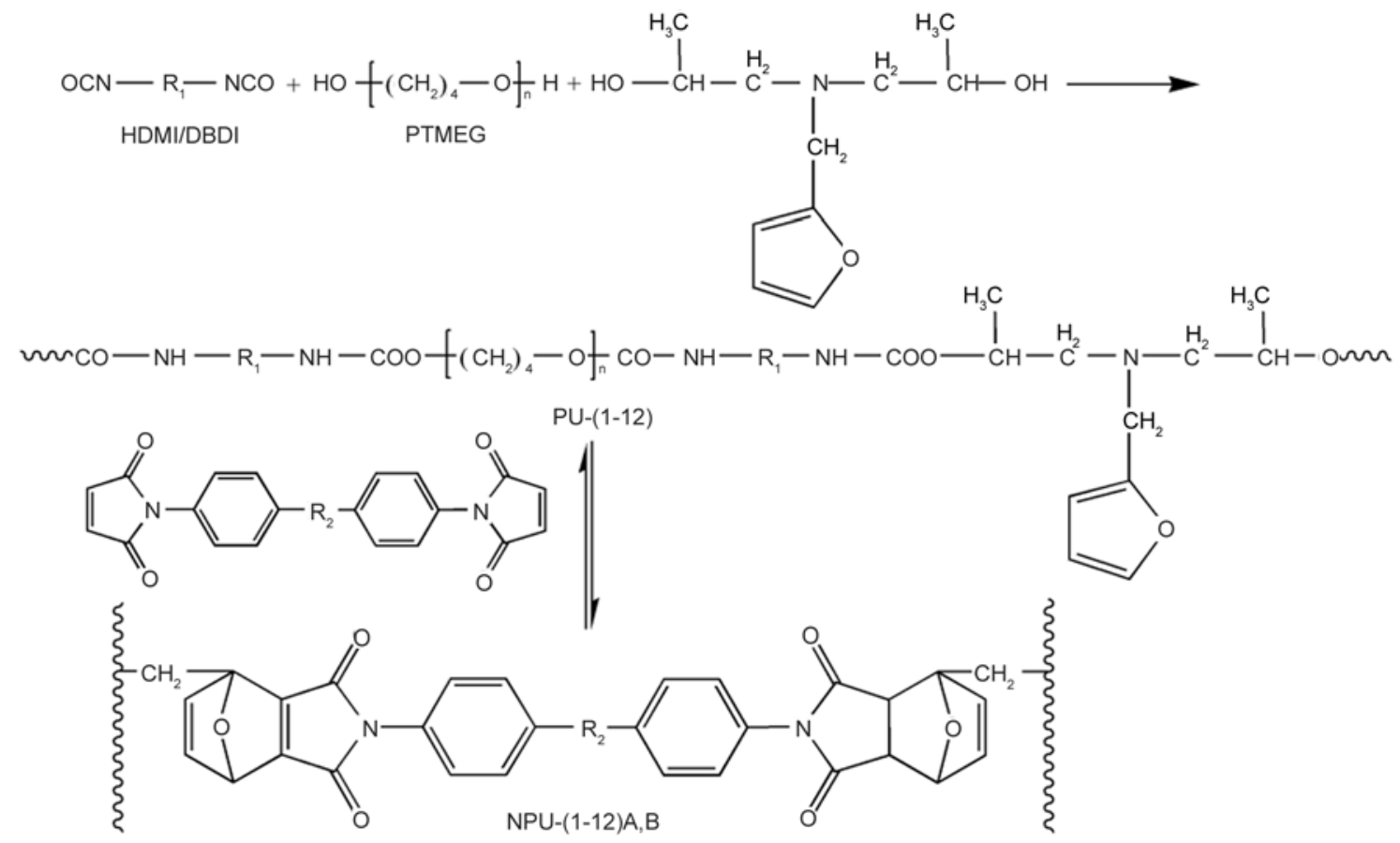

Figure 1. Synthesis of poly(ether-urethane) networks 
Table 1. The composition of polyurethanes and their networks

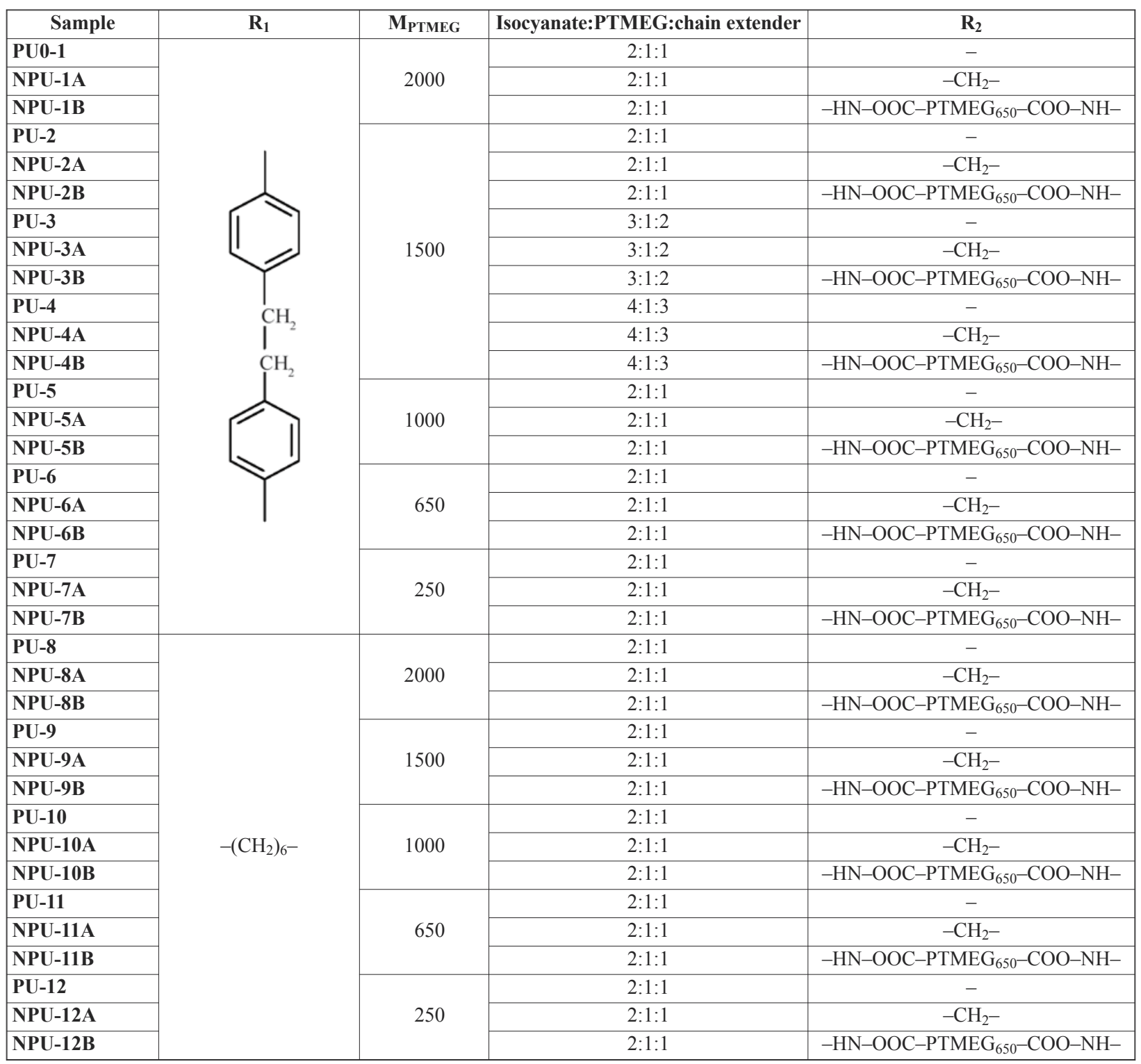

PTMEG (having number-average molecular weight of $250,650,1000,1500$ and 2000) and $2-[N, N-$ bis(2-methyl-2-hydroxyethyl)amino]furfuryl in molar ratio of $2: 1: 1,3: 1: 2$ or $4: 1: 3$ as represented in Figure 1 and Table 1 . The FT-IR and ${ }^{1} \mathrm{H}-\mathrm{NMR}$ spectroscopy were used to investigate the formation of polyurethanes. Typical infrared spectra of synthesized polyurethanes are shown in Figure 2. They did not show the absorption band at $2270 \mathrm{~cm}^{-1}$ associated with isocyanate group. The ATR-FTIR spectra of the polyurethane elastomers PU-(1-12) exhibited the bonds typical for the polyurethanes. As can be observed in Figure 2 the intensity of the absorption bands at $1105 \mathrm{~cm}^{-1}$ corresponding to ether linkage decreased with decreasing the number-average molecular weight of PTMEG. The same behavior could be observed in the case of the

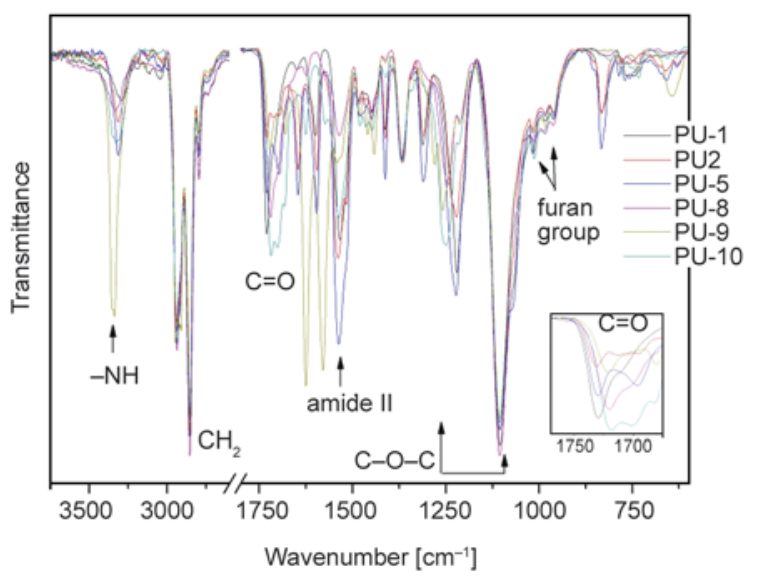

Figure 2. The ATR-FTIR spectra of polyurethanes

absorption band characteristic to the vibration of methylene group. These phenomena were expected 
since a lower number-average molecular weight of PTMEG used in synthesis led to a decrease of the ether linkages and methylene groups ratio in the polyurethane structure.

The ${ }^{1} \mathrm{H}-\mathrm{NMR}$ spectra of polyurethanes presented suitable signals for $\mathrm{NH}$ from urethane groups, $\mathrm{CH}_{3}$, $\mathrm{CH}_{2}$ from polyether glycol and diisocyanate, aromatic protons from DBDI structures, furan protons from chain extender. Representative ${ }^{1} \mathrm{H}-\mathrm{NMR}$ spectra of PU-7 and PU-12 were presented in Figure 3. The protons corresponding to the furyl group appeared at $6.38,6.27$ and $7.57 \mathrm{ppm}$, the protons specific to the $\mathrm{NH}$ from aliphatic structure from PU-12 at $7.01 \mathrm{ppm}$ and those specific to the aromatic structure from PU-7 appeared at 6.29, 6.40, 7.57 and 9.41-9.46 (-N $\left.\underline{\mathrm{H}}-\mathrm{C}_{6} \mathrm{H}_{4}-\right) \mathrm{ppm}$. The ratio between integral area of furan and isocyanate protons of the obtained polymers is in agreement with the composition of the mixture used for synthesis (isocyanate:chain extender of 1:2).
The composition and inherent viscosity of PU-(112) were presented in Table 1 and Table 2 . The cal-

Table 2. Properties of polyurethanes PU-(1-12)

\begin{tabular}{|l|c|c|c|c|c|}
\hline Sample & $\begin{array}{c}\boldsymbol{\eta}_{\mathbf{i n h}^{\mathbf{a}}} \\
{[\mathbf{d L} / \mathbf{g}]}\end{array}$ & $\mathbf{M}_{\mathbf{w}}{ }^{\mathbf{b}}$ & $\mathbf{P D I}^{\mathbf{c}}$ & $\begin{array}{c}\text { Hard } \\
\text { segment } \\
\text { content } \\
{[\%]}\end{array}$ & $\begin{array}{c}\text { Furyl } \\
\text { monomer } \\
\text { content } \\
{[\mathbf{m o l} / \mathbf{g}]}\end{array}$ \\
\hline PU-1 & 0.33 & 38303 & 1.28 & 27.54 & $3.65 \cdot 10^{-4}$ \\
\hline PU-2 & 0.63 & 37877 & 1.34 & 33.63 & $4.46 \cdot 10^{-4}$ \\
\hline PU-3 & 0.54 & 20124 & 1.28 & 45.52 & $7.35 \cdot 10^{-4}$ \\
\hline PU-4 & 0.41 & 21447 & 1.30 & 53.34 & $9.38 \cdot 10^{-4}$ \\
\hline PU-5 & 0.37 & 24204 & 1.28 & 43.18 & $5.74 \cdot 10^{-4}$ \\
\hline PU-6 & 0.43 & 22306 & 1.28 & 53.90 & $7.18 \cdot 10^{-4}$ \\
\hline PU-7 & 0.23 & 21116 & 1.27 & 75.25 & $10.08 \cdot 10^{-4}$ \\
\hline PU-8 & 0.58 & 26023 & 1.28 & 21.62 & $3.92 \cdot 10^{-4}$ \\
\hline PU-9 & 0.83 & 34049 & 1.27 & 26.90 & $4.88 \cdot 10^{-4}$ \\
\hline PU-10 & 0.51 & 17519 & 1.29 & 35.56 & $6.45 \cdot 10^{-4}$ \\
\hline PU-11 & 0.78 & 23857 & 1.35 & 45.90 & $8.33 \cdot 10^{-4}$ \\
\hline PU-12 & 0.45 & 22950 & 1.27 & 68.82 & $12.50 \cdot 10^{-4}$ \\
\hline
\end{tabular}

${ }^{a}$ Inherent viscosity measured in DMF solution at $25^{\circ} \mathrm{C}$

${ }^{\mathrm{b}}$ The weight-average molecular weight

'Polydispersity index

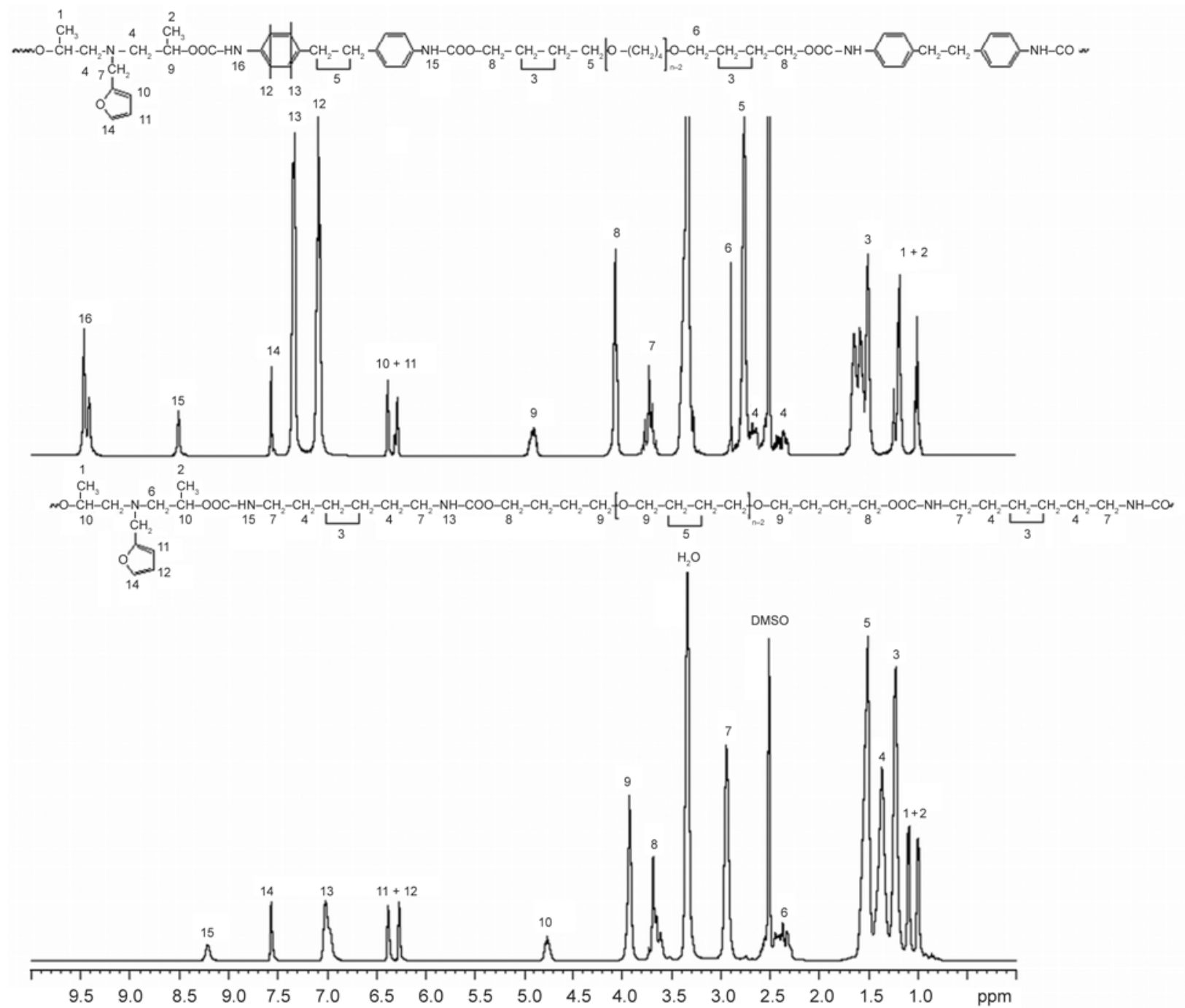

Figure 3. The ${ }^{1} \mathrm{H}-\mathrm{NMR}$ spectra of PU-7 and PU-12 
culated hard segment content (as calculated from the initial composition) varied between 21.62 to $75.25 \%$ and the furfuryl monomer content varied in the range of $3.65 \cdot 10^{-4}-12.50 \cdot 10^{-4} \mathrm{~mol} / \mathrm{g}$. The inherent viscosity measured in DMF solution at $25^{\circ} \mathrm{C}$ varied between 0.23 and $0.83 \mathrm{dL} / \mathrm{g}$ and decreased as the molar ratio of isocyanate: PTMEG:chain extender increases from 2:1:1 to 4:1:3. The weight-average molecular weight and polydispersity index were recorded on a PL-EMD 950 Evaporative light Detect instrument and reported in Table 2. As can be seen from Table 2, the weight-average molecular weight and polydispersity index decreased as the molar ratio of isocyanate:PTMEG:chain extender increased and the molecular weight of PTMEG decreased in the case of PU-(1-7). Weight-average molecular weights and the polydispersity index of the polyurethanes were in the range of 1751938303 and $1.27-1.35$, respectively.

The polyurethane networks NPU-(1-12)A,B were prepared by the Diels-Alder crosslinking reaction of PU-(1-12) to 4,4'-bismaleimidodiphenylmethane (A) or oligoether urethane bismaleimide (B), as represented in Figure 1. The composition of polymers and networks is presented in Table 1.

The ATR-FTIR spectra of networks (Figure 4) showed the disappearance of the furan ring breathing absorption band at $1012 \mathrm{~cm}^{-1}$ and the appearance of new bands at $1775(\mathrm{C}=\mathrm{O}$ cycloadduct $)$ and $1192 \mathrm{~cm}^{-1}(\mathrm{C}-\mathrm{N}-\mathrm{C}$ succinimide ring from cycloadduct) attributed to the furan-maleimide cycloadduct [45]. The shifting absorption band characteristic to the carbonyl group to lower wavenumbers represents another confirmation of the formation of

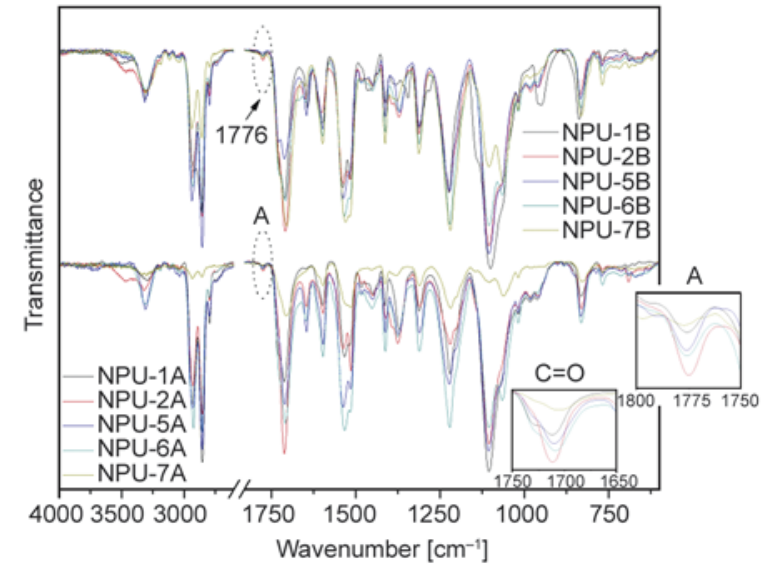

Figure 4. The ATR-FTIR spectra of networks the Diels-Alder cyclodduct. Also, it was observed a change in the absorption bands characteristic to the non-bonded and bonded urethane $\mathrm{C}=\mathrm{O}$ at 1680 $1720 \mathrm{~cm}^{-1}$.

\subsection{Thermal properties}

Urethanes are known to be relatively thermally unstable materials and the decomposition temperature of the urethane bond depends on the polyurethane structure. Thus, the polyurethanes and their corresponding networks based on alkyl structure (PU- and NPU-(8-12)) presented a better thermal stability than the ones based on aryl structure (PUand NPU-(1-7)). There have been proposed three mechanisms for the decomposition of urethane bonds: dissociation to isocyanate and alcohol, formation of primary amine and olefin, and formation of secondary amine and carbon dioxide. These reactions may proceed simultaneously or separately. Figure 5 presents the thermal degradation curves of polyurethane networks NPU-(1-2,5-7)A. As can be seen the decomposition of the urethane bonds proceeded in two stages, meaning that two of the reactions mentioned above were overlapping. These two stages ranged between $202-398^{\circ} \mathrm{C}$ (Table 3 ). At higher temperatures, the decomposition stage was due to the degradation of PTMEG chain and to the other units from the polyurethane network, and ranged between $381-517^{\circ} \mathrm{C}$. As expected, the weight loss corresponding to the first two stages increased with decreasing the number-average molecular weight of PTMEG since the urethane linkages ratio in network was higher. On the other hand the weight loss of the third stage decreased due to the fact that

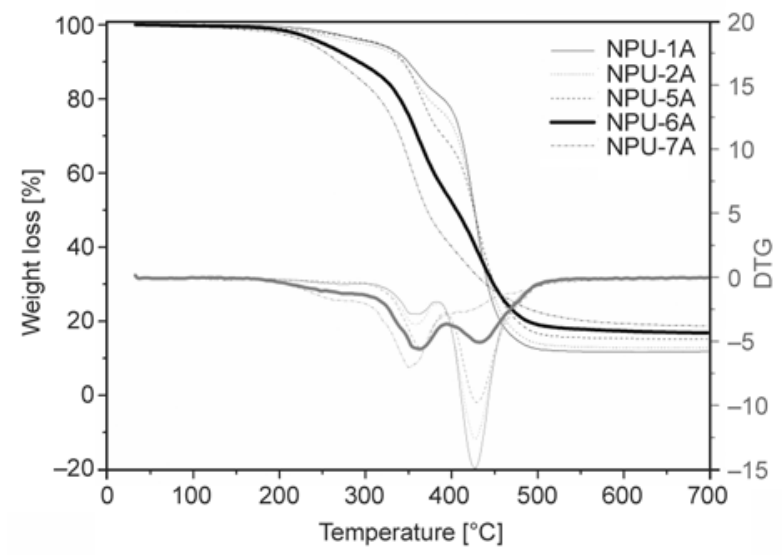

Figure 5. The TGA curves of NPU-(1-7)A with a isocyanate:PTMEG:chain extender molar ratio of $2: 1: 1$ 
Table 3. The thermogravimetric data of PU and NPU

\begin{tabular}{|c|c|c|c|c|}
\hline \multirow{2}{*}{ Sample } & \multicolumn{3}{|c|}{ Weight loss/decomposition temperature $\left[\% /{ }^{\circ} \mathrm{C}\right]$} & \multirow{2}{*}{$\begin{array}{c}\mathbf{Y}_{\mathbf{c}}{ }^{\mathbf{a}} \\
{\left[{ }^{\circ} \mathbf{C}\right]}\end{array}$} \\
\hline & Step I & Step II & Step III & \\
\hline NPU-1A & $4.20 / 216-286$ & $13.08 / 332-370$ & $70.12 / 402-466$ & 11.88 \\
\hline PU-2 & $16.00 / 220-340$ & $52.00 / 390-465$ & $18.40 / 470-550$ & 6.00 \\
\hline NPU-2A & $4.90 / 160-279$ & $17.30 / 329-371$ & $64.78 / 398-475$ & 12.80 \\
\hline NPU-2B & $5.20 / 208-281$ & $22.40 / 312-379$ & $34.40 / 396-460$ & 8.00 \\
\hline NPU-5A & $3.76 / 209-285$ & $24.40 / 313-376$ & $55.54 / 398-494$ & 15.25 \\
\hline NPU-6A & $13.00 / 189-290$ & $33.22 / 320-378$ & $36.00 / 409-482$ & 16.90 \\
\hline PU-7 & $14.00 / 200-278$ & $42.80 / 312-392$ & $30.80 / 409-492$ & 11.30 \\
\hline NPU-7A & $13.50 / 215-287$ & $35.16 / 308-370$ & $31.00 / 398-455$ & 18.70 \\
\hline NPU-7B & $8.70 / 213-274$ & $36.50 / 318-371$ & $38.10 / 410-483$ & 15.60 \\
\hline PU-10 & $23.20 / 245-367$ & $45.60 / 360-446$ & $10.00 / 455-600$ & 6.00 \\
\hline NPU-10A & $26.80 / 240-350$ & $43.60 / 383-455$ & $92.00 / 460-580$ & 11.20 \\
\hline NPU-10B & $30.00 / 260-380$ & $46.40 / 385-460$ & $16.00 / 465-600$ & 5.00 \\
\hline
\end{tabular}

${ }^{\mathrm{a}} \mathrm{Char}$ yield at $600^{\circ} \mathrm{C}$

this decomposition step was due mainly due to the degradation of PTMEG chains.

Figure 6 shows the thermal behavior of the weight loss curves of PU-7, NPU-7A and NPU-7B. The shape of the weight loss curves of all samples was almost identical. The increase of the weight loss in the degradation second step of NPU-7B was due to the presence of the soft segment from bismaleimide.
DSC analysis provided the information on the glass transition, crystallization, melting endotherms and also the rDA reaction of networks (Figure 7 and Figure 8). The DSC data are compiled in Table 4. Figure 7 present DSC curves of networks based on polyurethanes PU-(1-7) and bismaleimide A (Figure 7a) or B (Figure 7b). DSC curves of NPU-(27)A (Figure 7a) exhibited the glass transition temperature corresponding to the soft segment, the glass

Table 4. Thermal behavior of polyurethane networks

\begin{tabular}{|c|c|c|c|c|c|c|}
\hline Sample & $\begin{array}{l}T_{g_{s ~ s}{ }^{a}} \\
{\left[{ }^{\circ} \mathbf{C}\right]}\end{array}$ & $\begin{array}{c}\mathbf{T}_{\text {cryst ss }} \mathbf{b} \\
{\left[{ }^{\circ} \mathbf{C}\right]}\end{array}$ & $\begin{array}{c}\mathbf{T}_{\text {melt ss }}{ }^{\mathrm{c}} \\
{\left[{ }^{\circ} \mathrm{C}\right]}\end{array}$ & $\begin{array}{c}T_{g \text { network }}{ }^{d} \\
{\left[{ }^{\circ} \mathrm{C}\right]}\end{array}$ & $\begin{array}{l}\mathrm{T}_{\text {TDA }}{ }^{\mathrm{e}} \\
{\left[{ }^{\circ} \mathrm{C}\right]}\end{array}$ & $\begin{array}{c}\Delta \mathbf{H}_{\mathrm{rDA}} \\
{[\mathbf{J} / \mathrm{g}]}\end{array}$ \\
\hline NPU-2A & -64.47 & - & -2.58 & - & 120.14 & -12.96 \\
\hline NPU-3A & -62.86 & - & - & 54.80 & 109.55 & -44.38 \\
\hline NPU-4A & -66.18 & - & - & 53.32 & 112.44 & -38.84 \\
\hline NPU-5A & -59.36 & - & - & - & 116.21 & -3.44 \\
\hline NPU-6A & -36.06 & - & - & 53.11 & 109.12 & -18.79 \\
\hline NPU-7A & - & - & - & 52.06 & 104.25 & -22.29 \\
\hline NPU-8A & -72.25 & -34.54 & 22.72 & - & 117.46 & -16.74 \\
\hline NPU-9A & -68.31 & - & 2.59 & - & 150.49 & - \\
\hline NPU-10A & -57.76 & - & - & - & 116.17 & - \\
\hline NPU-11A & -45.32 & - & - & - & 117.71 & -30.65 \\
\hline NPU-12A & 12.32 & - & - & - & 112.35 & -91.16 \\
\hline NPU-1B & -69.25 & -23.05 & 16.34 & 50.98 & 106.21 & -2.40 \\
\hline NPU-5B & -56.08 & - & - & 46.20 & 121.17 & -3.06 \\
\hline NPU-6B & -32.29 & - & - & 41.93 & 108.89 & -13.76 \\
\hline NPU-7B & - & - & - & 20.51 & 109.18 & -46.73 \\
\hline NPU-8B & -72.34 & -36.00 & 17.65 & - & 115.46 & -6.95 \\
\hline NPU-9B & -69.93 & - & 8.20 & - & 109.82 & -63.92 \\
\hline NPU-10B & -60.73 & - & - & 46.08 & 113.18 & -13.02 \\
\hline NPU-11B & -48.69 & - & - & 48.05 & 113.05 & -14.62 \\
\hline NPU-12B & 8.34 & - & - & - & 113.44 & -44.91 \\
\hline
\end{tabular}

${ }^{\mathrm{a}}$ Glass transition temperature of soft segment polyurethanes

${ }^{\mathrm{b}}$ Crystallization temperature of soft segment polyurethanes

${ }^{\mathrm{c}}$ Melting temperature of soft segment polyurethanes

${ }^{\mathrm{d}}$ Glass transition temperature of networks

${ }^{\mathrm{e}}$ Temperature corresponding to retro Diels-Alder reaction

${ }^{\mathrm{f}} \mathrm{Heat}$ of the retro Diels-Alder reaction 
transition temperature corresponding to networks and endothermic transition temperature corresponding to the rDA process, and varied in the range of --36.06 and $-66.18^{\circ} \mathrm{C}, 50-55^{\circ} \mathrm{C}$ and $104-120^{\circ} \mathrm{C}$, respectively. The networks based on PTMEG hav-

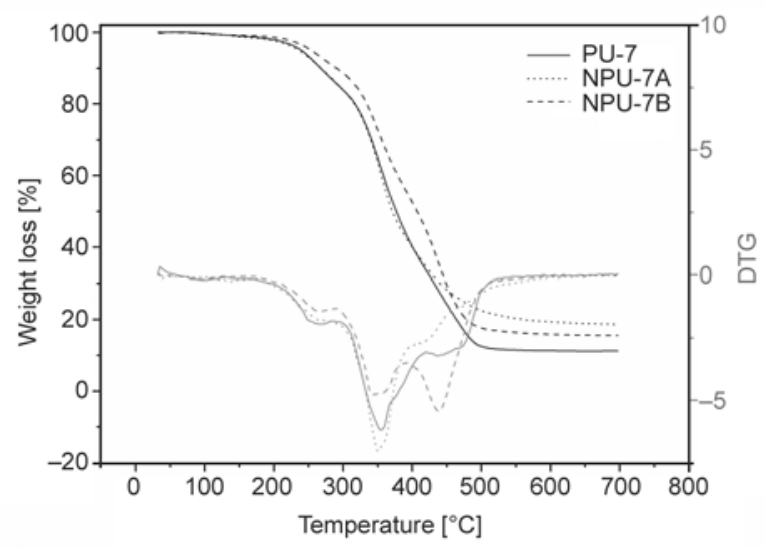

Figure 6. The TGA curves of PU-7 and its corresponding networks ing number-average molecular weight of 250 , NPU-7A, did not show $T_{\mathrm{g}}$ for soft segment. The rDA process energy ranged between -3.44 and $-44.38 \mathrm{~J} / \mathrm{g}$ depending on the number-average molecular weight of PTMEG and the isocyanate: PTMEG:chain extender molar ratio. DSC curves for networks NPU-(1-7)B showed the same transitions and endothermic process whose maximum temperature ranged between $106-121^{\circ} \mathrm{C}$. On the DSC curves of polyurethane networks NPU-(17)A,B there can be observed that when decreasing the number-average molecular weight of PTMEG the $T_{\mathrm{g}}$ of network and $T_{\mathrm{g}}$ of the soft segment increased due to the fact that as the PTMEG chain's length decreases, it's mobility decreases too, leading this way to a higher glass transition temperature. The decrease of the $T_{\mathrm{g}}$ of soft segment when increasing the number-average molecular weight of PTMEG indicates that longer soft segments present a better phase separation in the corresponding poly-
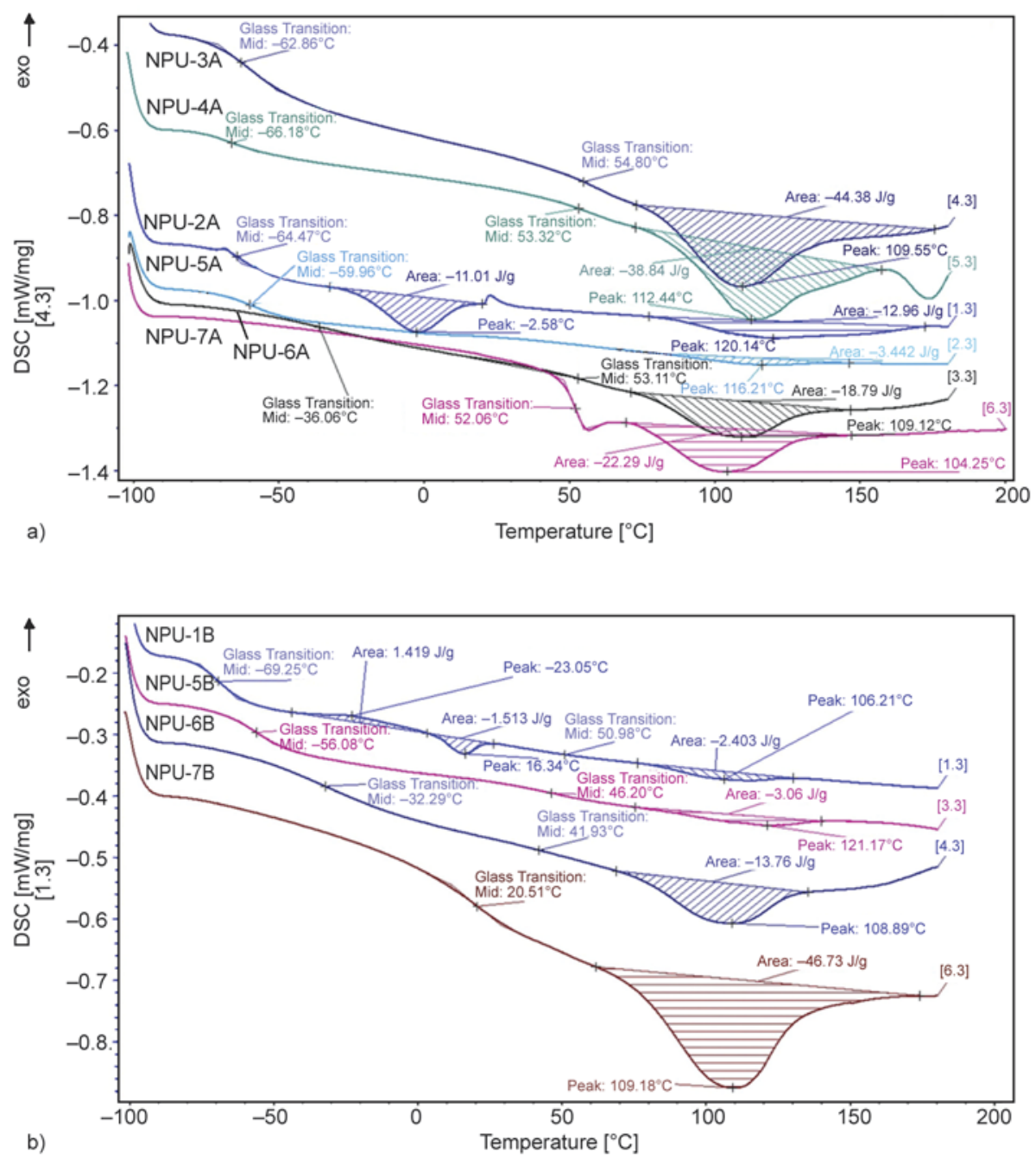

Figure 7. The DSC curves of networks based on DBDI; (a) with bismaleimide A; (b) with bismaleimide B 

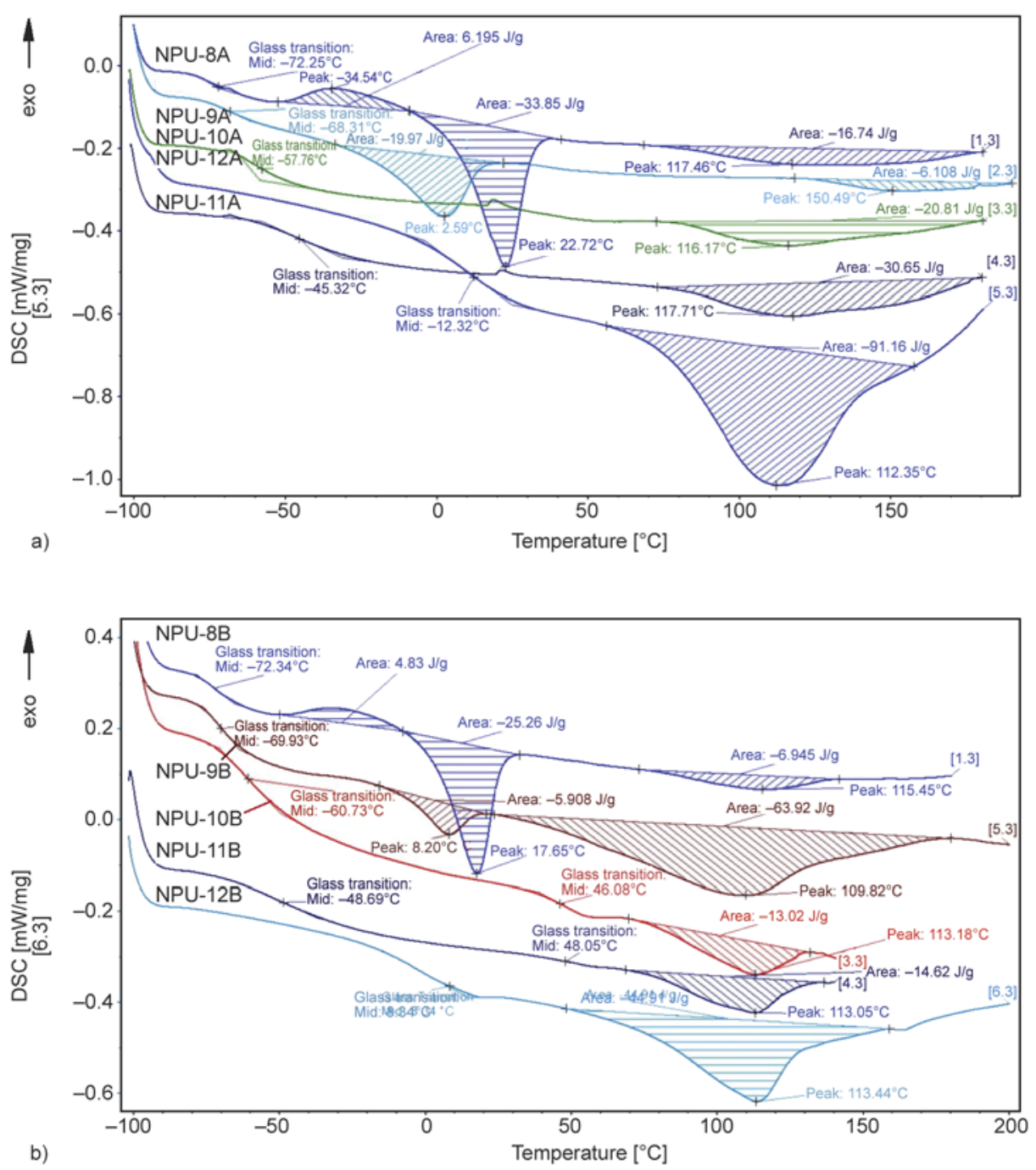

Figure 8. The DSC curves of networks based on HMDI; (a) with bismaleimide A; (b) with bismaleimide B

urethane network [46]. Also, by increasing the molar ratio (amount of chain extender) the crosslinking density increases (this was evidenced by the disappearance of melting endotherm of the soft segment) and the glass transition temperature of network slightly decreases, probably due to the longer segment lengths between network points.

The DSC curves of polyurethane networks NPU(8-12)A,B are represented in Figure $8 \mathrm{a}$ and $8 \mathrm{~b}$. There can be observed that the curves presented the same characteristics as the ones of NPU-(1-7)A,B. Also, there can be noticed that using DBDI instead of HMDI in the synthesis of polyurethanes leads to a higher glass transition temperature of the soft segment.

Regarding the crystallization and melting processes from both Figures 7 and Figure 8 one can see that only the DSC curves of NPU-(1,8)A,B which contain PTMEG having the number-average molecular weight of 2000 presented the crystallization exotherm, while the melting endotherm was present on the DSC curves of polyurethane networks which had PTMEG with the number-average molecular weight of 2000 and 1500 . In the case of the networks with lower number-average molecular weight of PTMEG none of these processes could be observed, their molecular weight being too low to evidence a crystallization process [47].

\subsection{Thermoreversibility of the networks}

The DSC and ATR-FTIR methods were applied to evaluate the thermoreversibility of the networks. The thermoreversibility of the network (NPU-11A) was evidenced by applying multiple heating-cooling cycles in a differential scanning calorimeter. Thus, there can be observed that the endothermic peak characteristic to the retrodienic process appeared on all three heating curves, the maximum 


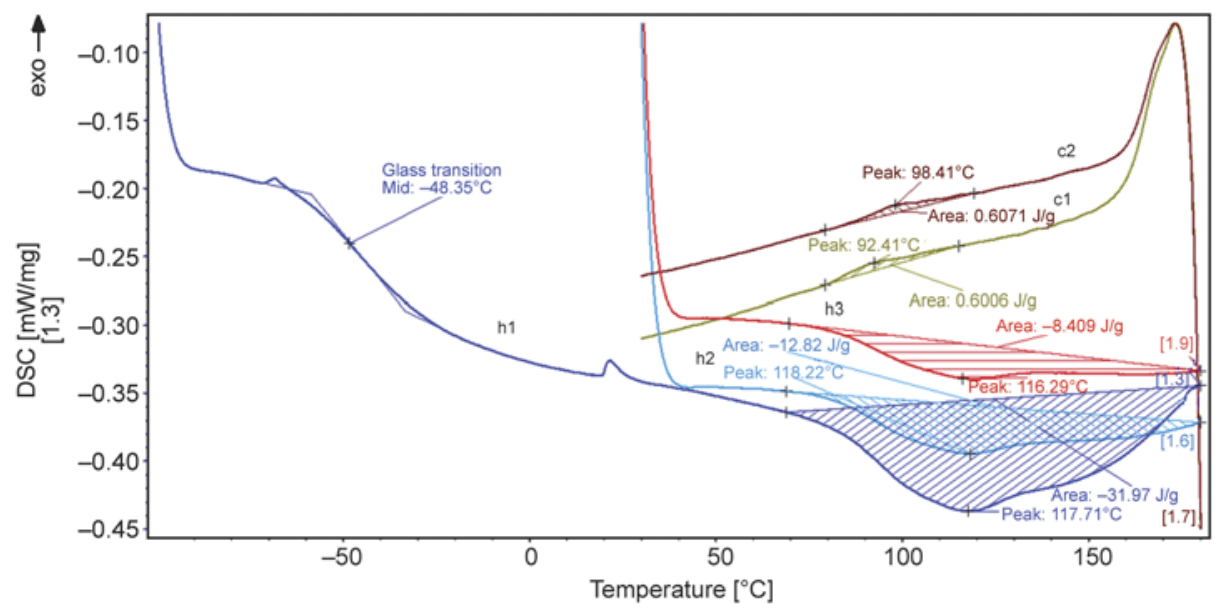

Figure 9. The DSC scans of NPU-11A: h1 - the first heating run; h2 - the second heating run and h3 - the third heating run; $\mathrm{c} 1$ - the first cooling run; $\mathrm{c} 2$ - the second cooling run

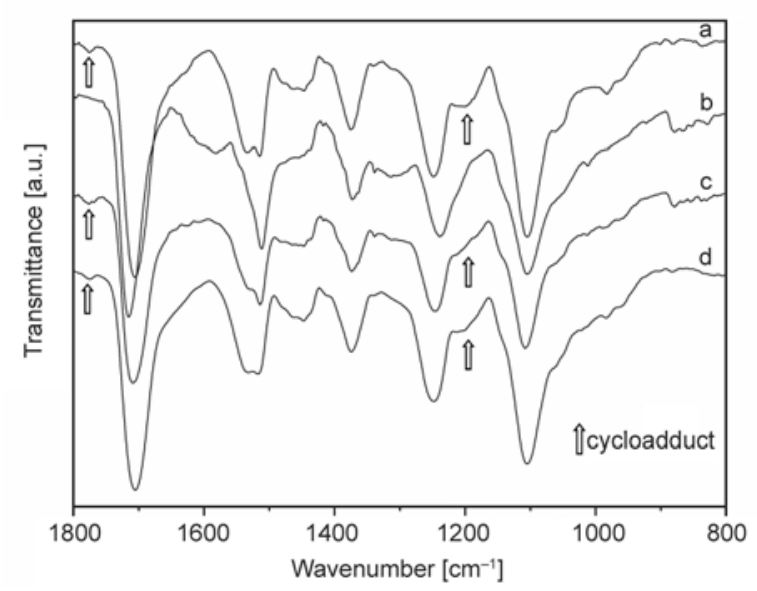

Figure 10. The ATR-FTIR spectra of NPU-11A: a - initial; $\mathrm{b}-$ at $150^{\circ} \mathrm{C}$; c - after cooling; $\mathrm{d}$ - recovery (after heat treatment at $80^{\circ} \mathrm{C}$ for 6 hours)

of the endothermic peak having almost the same value around $116-118^{\circ} \mathrm{C}$ (Figure 9). The cooling curves presented an exothermic peak with a maximum around $92-96^{\circ} \mathrm{C}$, exotherm which is specific to the dienic process of regeneration of the furanmaleimide cycloadduct.

The thermoreversibility of NPU-11A was also confirmed by ATR-FTIR spectroscopy (Figure 10). So, recording the spectrum for this compound at $130^{\circ} \mathrm{C}$ (Figure 10 curve b) we can observed that it was not present anymore the characteristic band of cycloadduct at $1775 \mathrm{~cm}^{-1}$ and also that the band attributed to the carbonyl stretching vibration shifted to higher values $\left(1714 \mathrm{~cm}^{-1}\right)$. The $-\mathrm{C}-\mathrm{N}-\mathrm{C}-$ absorption band from succinimide at $1197 \mathrm{~cm}^{-1}$ disappeared too due to the debonding of the cycloadduct in maleimide and furyl groups. After cooling the sample and recording again the spectrum, we could see that the carbonyl band shifted back to lower val-

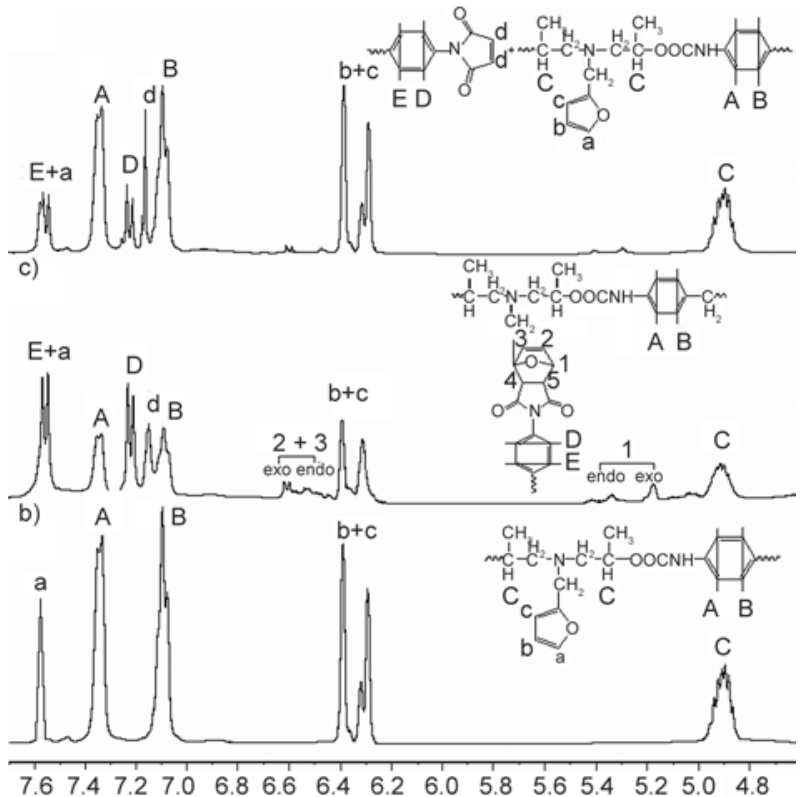

a)

Figure 11. The ${ }^{1} \mathrm{H}-\mathrm{NMR}$ spectra of Diels-Alder cycloaddition after different time periods: (a) PU-7B; (b) after $10 \mathrm{~h}$ at $60^{\circ} \mathrm{C}(\mathbf{N P U}-7 \mathbf{B})$; (c) retro-DA (PU-7B + bismaleimide B)

ues $\left(1711 \mathrm{~cm}^{-1}\right)$ and the appearance of the band at $1775 \mathrm{~cm}^{-1}$ corresponding to the cycloadduct and the one at $1197 \mathrm{~cm}^{-1}$ attributed to $-\mathrm{C}-\mathrm{N}-\mathrm{C}-$ from succinimide (Figure 10 curve c). After heating the sample at $80^{\circ} \mathrm{C}$ for 6 hours in an oven the carbonyl band shifts back to it's initial value $\left(1708 \mathrm{~cm}^{-1}\right)$ due to the complete recovery of the cycloadduct when an appropriate time was accorded to the dienic reaction took place (Figure 10 curve d).

The reaction between furyl and maleimide groups was carried out at different temperatures (60 and $140^{\circ} \mathrm{C}$ ) in DMSO- $\mathrm{d}_{6}$ (NMR tube under nitrogen atmosphere) allowing real-time ${ }^{1} \mathrm{H}-\mathrm{NMR}$ character- 
ization. The evolution of ${ }^{1} \mathrm{H}-\mathrm{NMR}$ spectra were shown in Figure 11. Figure 11a represents the ${ }^{1} \mathrm{H}-\mathrm{NMR}$ spectrum of PU-7B. After reacting PU-7 B with bismaleimide $\mathbf{B}$ at $60^{\circ} \mathrm{C}$ for $10 \mathrm{~h}$, part of formed network becomes insoluble; the ${ }^{1} \mathrm{H}-\mathrm{NMR}$ spectrum exhibits new signals at 6.65-6.43, and 5.45$5.17 \mathrm{ppm}$ assigned to exo/endo protons 2,3 , and 1 of DA adduct, respectively, along with the existing peaks at $7.57 \mathrm{ppm}$ attributed to protons a from furyl unity, and at $6.42-6.25 \mathrm{ppm}$ ascribed to protons $\mathrm{b}$ and c of furyl group (Figure 11 (b)). After complete Diels-Alder reaction, the sample became a gel and the ${ }^{1} \mathrm{H}-\mathrm{NMR}$ spectrum could not be recorded. After the sample was heated at $140^{\circ} \mathrm{C}$, the corresponding
${ }^{1} \mathrm{H}-\mathrm{NMR}$ spectrum exhibited the signals characteristic to the bismaleimide $\mathbf{B}$ (7.14 ppm assigned to the proton d) and PU-7B (Figure 11c).

\subsection{Surface characterization of the networks}

The dynamic contact angles of the polyurethanes and polyurethane networks were measured using Wilhelmy plate technique. The advancing contact angle values measured in water and ethylene glycol and the hysteresis values are given in Table 5. The free surface energies were calculated according to Owens and Wendt equation (Equation (1)):

$$
(1+\cos \theta) \gamma_{L}=2\left(\gamma_{S}{ }^{d} \gamma_{L}^{d}\right)^{1 / 2}+2\left(\gamma_{S}^{p}+\gamma_{L}^{p}\right)^{1 / 2}
$$

Table 5. Contact angle in water and ethylene glycol and dispersive and polar components of free energy of PU and NPU films

\begin{tabular}{|c|c|c|c|c|c|c|c|}
\hline \multirow{2}{*}{ Sample } & \multirow{2}{*}{$\theta_{\text {adv water }}{ }^{\mathrm{a}} /$ hysteresis } & \multirow{2}{*}{$\theta_{\text {adv EG }}$ b/hysteresis } & \multicolumn{2}{|c|}{$\Delta \mathbf{G}_{\mathrm{h}}{ }^{\mathrm{c}}$} & \multicolumn{3}{|c|}{ Free surface energy $^{d}$} \\
\hline & & & Water & EG & $\gamma^{d}$ & $\gamma^{p}$ & $\gamma=\gamma^{\mathrm{d}}+\gamma^{\mathrm{p}}$ \\
\hline PU-1 & $91.85 / 32.26$ & $81.56 / 50.76$ & 0.365 & 1.631 & 5.642 & 11.420 & 17.062 \\
\hline PU-2 & $87.26 / 22.60$ & $75.78 / 22.60$ & 0.248 & 1.235 & 6.801 & 13.217 & 20.018 \\
\hline PU-3 & $93.35 / 34.09$ & $78.90 / 34.09$ & 0.371 & 1.100 & 9.227 & 7.923 & 17.409 \\
\hline PU-4 & $85.66 / 36.77$ & $76.68 / 38.21$ & 0.669 & 1.110 & 4.932 & 16.246 & 21.178 \\
\hline PU-5 & $92.89 / 26.14$ & $82.51 / 36.34$ & 0.207 & 0.788 & 5.659 & 10.789 & 16.448 \\
\hline PU-6 & $96.98 / 43.48$ & $73.98 / 34.38$ & 0.522 & 1.023 & 19.188 & 2.603 & 21.791 \\
\hline PU-8 & $87.00 / 29.07$ & $84.73 / 26.80$ & 0.406 & 1.148 & 1.240 & 21.487 & 22.727 \\
\hline PU-9 & $84.10 / 29.96$ & $76.43 / 37.31$ & 0.420 & 1.071 & 4.094 & 18.473 & 22.567 \\
\hline PU-10 & $70.57 / 18.30$ & $64.30 / 18.30$ & 0.435 & 1.250 & 3.583 & 30.856 & 34.439 \\
\hline PU-11 & $76.97 / 23.64$ & $64.01 / 30.25$ & 0.481 & 1.192 & 8.269 & 19.063 & 27.332 \\
\hline PU-12 & $89.19 / 34.81$ & $76.82 / 46.08$ & 0.543 & - & 7.494 & 11.419 & 18.913 \\
\hline NPU-1A & $87.41 / 20.76$ & $84.14 / 58.37$ & 0.209 & 2.051 & 1.622 & 20.202 & 21.824 \\
\hline NPU-2A & $77.20 / 29.55$ & $75.78 / 29.25$ & 0.687 & 1.010 & 1.181 & 30.421 & 31.602 \\
\hline NPU-3A & $86.88 / 31.65$ & $75.00 / 43.21$ & 0.492 & 1.501 & 7.162 & 13.138 & 20.300 \\
\hline NPU-4A & $73.42 / 16.91$ & $63.81 / 27.77$ & 0.356 & 1.050 & 9.666 & 24.951 & 30.617 \\
\hline NPU-5A & $83.29 / 28.38$ & $73.50 / 34.88$ & 0.480 & 1.064 & 5.606 & 17.177 & 22.783 \\
\hline NPU-6A & $84.16 / 28.78$ & $70.81 / 15.43$ & 0.470 & 0.862 & 8.544 & 13.723 & 22.267 \\
\hline NPU-8A & $89.87 / 31.53$ & $77.84 / 38.71$ & 0.399 & 1.084 & 7.167 & 11.277 & 18.444 \\
\hline NPU-9A & $91.59 / 45.35$ & $82.24 / 20.53$ & 0.805 & 0.292 & 4.948 & 12.258 & 17.206 \\
\hline NPU-10A & $92.30 / 30.34$ & $82.58 / 52.81$ & 0.307 & 1.713 & 5.185 & 11.584 & 16.769 \\
\hline NPU-11A & $82.28 / 25.43$ & $71.74 / 35.50$ & 0.418 & 0.954 & 6.210 & 17.242 & 23.452 \\
\hline NPU-12A & $86.03 / 29.71$ & $74.03 / 37.15$ & 0.449 & 1.167 & 7.249 & 13.572 & 20.866 \\
\hline NPU-1B & $88.84 / 31.47$ & $81.31 / 31.49$ & 0.425 & 2.368 & 3.825 & 15.377 & 19.202 \\
\hline NPU-2B & $75.05 / 19.93$ & $56.84 / 19.93$ & 0.405 & 1.642 & 13.106 & 16.362 & 29.468 \\
\hline NPU-4B & $90.60 / 36.63$ & $91.62 / 71.54$ & 0.526 & 2.650 & 0.278 & 22.079 & 22.357 \\
\hline NPU-5B & $85.88 / 29.50$ & $70.60 / 35.61$ & 0.447 & 1.233 & 10.354 & 11.285 & 21.630 \\
\hline NPU-6B & $82.47 / 31.56$ & $76.61 / 43.25$ & 0.606 & 1.413 & 3.051 & 21.370 & 24.420 \\
\hline NPU-7B & $86.19 / 31.20$ & $74.95 / 35.47$ & 0.489 & 1.035 & 6.650 & 14.060 & 20.710 \\
\hline NPU-9B & $81.79 / 27.11$ & $74.24 / 39.62$ & 0.479 & 1.256 & 3.472 & 21.220 & 24.692 \\
\hline NPU-10B & $88.80 / 36.70$ & $82.59 / 36.70$ & 0.574 & - & 3.261 & 16.184 & 19.445 \\
\hline NPU-11B & $88.39 / 45.53$ & $67.65 / 53.08$ & 0.954 & - & 16.544 & 6.698 & 23.153 \\
\hline NPU-12B & $83.37 / 27.71$ & $78.16 / 36.63$ & 0.459 & 1.045 & 3.812 & 19.438 & 23.250 \\
\hline
\end{tabular}

${ }^{a}$ Advanced contact angle measured in water

${ }^{\mathrm{b}}$ Advanced contact angle measured in ethylene glycol

cMolar free energy of hysteresis

${ }^{\mathrm{d}}$ Calculated from the dispersive $\left(\gamma^{\mathrm{d}}\right)$ and polar $\left(\gamma^{\mathrm{p}}\right)$ components 
where $\theta$ represents the advancing contact angle value, $\gamma_{\mathrm{L}}$ is the free surface energy of the liquid, $\gamma_{\mathrm{L}}{ }^{\mathrm{d}}$ and $\gamma_{\mathrm{L}}{ }^{\mathrm{p}}$ are the dispersive and polar components of the free surface energy of the liquid, and $\gamma_{\mathrm{S}}{ }^{\mathrm{p}}$ and $\gamma_{\mathrm{L}}{ }^{\mathrm{p}}$ are the dispersive and polar components of the free surface energy of the polyurethane/polyurethane network films.

The molar free energies of hysteresis, quantitatively correlation to surface interaction of the hysteresis, were also calculated using Equation (2):

$\Delta G_{\mathrm{h}}=-R T \ln \left(\frac{\sin \theta_{\mathrm{rec}}}{\sin \theta_{\text {adv }}}\right)$

where $\Delta G_{\mathrm{h}}$ is the molar free energy of hysteresis and $\theta_{\text {adv }}$ and $\theta_{\text {rec }}$ represent the advancing and receding dynamic contact angle values [48].

As can be observed, in the case of polyurethanes, the contact angle value depended on the nature of the isocyanate used in synthesis. Thus, PU-(8-12) had lower dynamic contact angle values than the corresponding PU-(1-7), due to the hydrophilic behavior of the aliphatic diisocyanate [49]. The contact angle value decreased when crosslinking PU-(1-7) with bismaleimides, while the free surface energy increased. On the score of crosslinking, the majority of the carbonyl and $\mathrm{NH}$ groups are not implied in hydrogen bonds anymore, thus being able to contribute to the increase of the hydrophilicity of the surface of polyurethane networks comparing with the ones of the polyurethanes. In the case of NPU-(8-12) the contact angle value increased comparing with the corresponding polyurethane (in most of the cases), even when the free surface energy increased. This fact can be due to the roughness of the surface, which is known to reduce the effective area of the contact angle, leading this way to higher values of it. As can be seen in Table 5 in the case of PU-(8-12) the surface roughness (given by the hysteresis value) increased when crosslinking with bismaleimides [50].

In most of the cases the polar component's value was higher than the dispersive one's indicating that the dipolar forces and the hydrogen bonds played an important role in the structure of the polyurethanes and polyurethane networks. The value of the molar free energy of hysteresis was higher in ethylene glycol than that in water, in most of the cases, suggesting that the contribution of dipolar forces and hydrogen bonds in water was more pregnant in ethylene glycol [48].

\subsection{Mechanical properties}

The investigated mechanical properties of the polyurethanes and polyurethane networks were: breaking strength and elongation and Young's modulus. By crosslinking the polyurethanes with bismaleimides there could be observed an increasing of the breaking elongation, elongation which can be even forth times higher (Figure 12a). The results of physico-mechanical measurements of poly(etherurethane)s evidenced a slight increase of the tensile strength from 5.51 to $6.30 \mathrm{MPa}$, and a decrease of the elongation at break (from 243.10 to $128.46 \%$ ), for a rate of reagents from $2: 1: 1$ to $3: 1: 2$. The breaking strength increased when crosslinking with bismaleimides increased, which was more pronounced
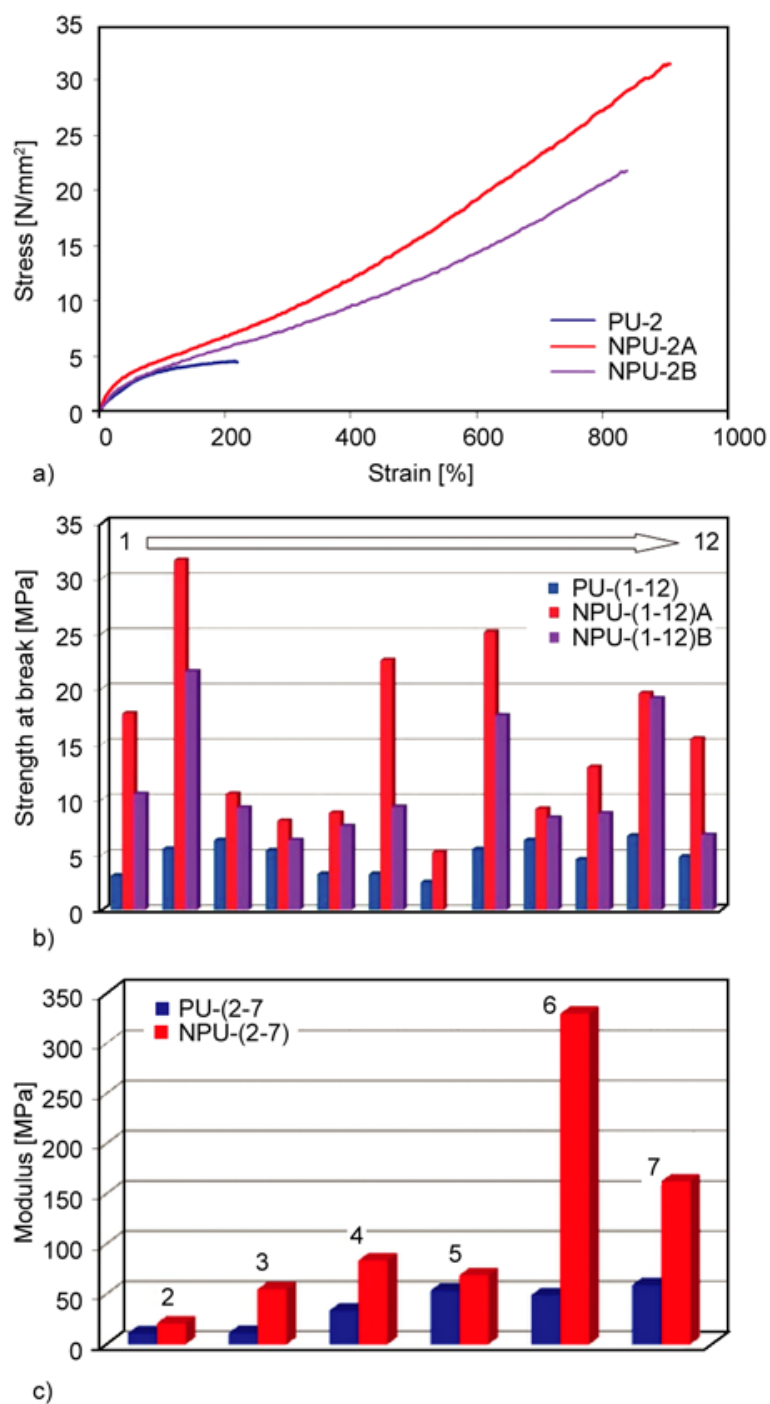

Figure 12. The mechanical properties of polyurethanes and their networks: (a) stress-strain diagram for PU-2 and its corresponding networks; (b) strength at break of polyurethanes and their networks; (c) modulus of PU-(2-7) and NPU-(2-7)A 
when using the aromatic bismaleimide (Figure 12b). The isocyanate:PTMEG:chain extender molar ratio used in this reaction also influenced the breaking strength. As can be seen in Figure 12b, an increase of the isocyanate and chain extender amount led to a decrease of the breaking strength. The Young's modulus of polyurethanes and polyurethane networks had the same behavior as breaking strength and elongation, meaning that it increased after crosslinking with bismaleimides (Figure 12c). Instead, unlike breaking strain, the modulus of the polyurethane networks increased when increasing the used isocyanate amount in synthesis, from 20.69 to 83.54 MPa for NPU-A and 8.28 to $57.60 \mathrm{MPa}$ for NPU-B.

\section{Conclusions}

Thermally reversible cross-linked poly(ether-urethane)s were prepared by the Diels-Alder crosslinking reaction of the furan-containing poly(ether-urethane) to bismaleimides. The glass transition temperature of the soft segment of DBDI-networks was higher than that of HDMI-networks and for both types of networks it decreased with increasing the molecular weight of PTMEG.

The thermal stability of networks was given by the both bismaleimide and isocyanate structure. The thermoreversibility of the networks was evidenced by both DSC and ATR-FTIR spectroscopy. The contact angle values of networks increased or decreased compared to that of polyurethanes depending on the isocyanate structure used in the synthesis. The bismaleimide structure and the used isocyanate: PTMEG:chain extender molar ratio influenced the mechanical properties of networks. By crosslinking the polyurethanes with bismaleimides there could be observed an increasing of the breaking elongation, elongation which can be even forth times higher than that of the initial polyurethane (900\%).

\section{References}

[1] Bergman S. D., Wudl F.: Mendable polymers. Journal of Materials Chemistry, 18, 41-62 (2008). DOI: $10.1039 / \mathrm{b} 713953 \mathrm{p}$

[2] Murphy E. B., Wudl F.: The world of smart healable materials. Progress in Polymer Science, 35, 223-251 (2010). DOI: $10.1016 /$ j.progpolymsci.2009.10.006
[3] Sanyal A.: Diels-Alder cycloaddition-cycloreversion: A powerful combo in materials design. Macromolecular Chemistry and Physics, 211, 1417-1425 (2010). DOI: $10.1002 / \mathrm{macp} .201000108$

[4] Hizal G., Tunca U., Sanyal A.: Discrete macromolecular constructs via the Diels-Alder 'click' reaction. Journal of Polymer Science Part A: Polymer Chemistry, 49, 4103-4120 (2011).

DOI: $10.1002 /$ pola.24835

[5] Boul P. J., Reutenauer P., Lehn J-M.: Reversible DielsAlder reactions for the generation of dynamic combinatorial libraries. Organic Letters, 7, 15-18 (2005). DOI: 10.1021/o1048065k

[6] Kotha S., Banerjee S., Patil M. P., Sunoj R. B.: Retro Diels-Alder reaction under mild conditions: experimental and theoretical studies. Organic and Biomolecular Chemistry, 4, 1854-1856 (2006).

DOI: $10.1039 / \mathrm{B} 604063 \mathrm{~B}$

[7] Jones G. O., Houk K. N.: Predictions of substituent effects in thermal azide 1,3-dipolar cycloadditions: Implications for dynamic combinatorial (reversible) and click (irreversible) chemistry. The Journal of Organic Chemistry, 73, 1333-1342 (2008).

DOI: $10.1021 /$ jo $702295 d$

[8] Reutenauer P., Boul P. J., Lehn J-M.: Dynamic DielsAlder reactions of 9,10-dimethylanthracene: reversible adduct formation, dynamic exchange processes and thermal fluorescence modulation. European Journal of Organic Chemistry, 2009, 1691-1697 (2009).

DOI: 10.1002/ejoc.200801269

[9] Boutelle R. C., Northrop B. H.: Substituent effects on the reversibility of furan-maleimide cycloadditions. The Journal of Organic Chemistry, 76, 7994-8002 (2011).

DOI: $10.1021 /$ jo201606z

[10] Pearson R. J., Kassianidis E., Philp D.: A completely selective and strongly accelerated Diels-Alder reaction mediated by hydrogen bonding. Tetrahedron Letters, 45, 4777-4780 (2004).

DOI: $10.1016 / j$.tetlet.2004.04.079

[11] Goiti E., Heatley F., Huglin M. B., Rego J. M.: Kinetic aspects of the Diels-Alder reaction between poly (styrene-co-furfuryl methacrylate) and bismaleimide. European Polymer Journal, 40, 1451-1460 (2004). DOI: 10.1016/j.eurpolymj.2004.01.036

[12] Conley N. R., Hung R. J., Willson C. G.: A new synthetic route to authentic $N$-substituted aminomaleimides. The Journal of Organic Chemistry, 70, 4553-4555 (2005). DOI: $10.1021 /$ jo048031q

[13] Teramoto N., Arai Y., Shibata M.: Thermo-reversible Diels-Alder polymerization of difurfurylidene trehalose and bismaleimides. Carbohydrate Polymers, 64, 78-84 (2006). DOI: $10.1016 /$ j.carbpol.2005.10.029 
[14] Dag A., Durmaz H., Hizal G., Tunca U.: Preparation of 3-arm star polymers $\left(\mathrm{A}_{3}\right)$ via Diels-Alder click reaction. Journal of Polymer Science Part A: Polymer Chemistry, 46, 302-313 (2008).

DOI: $10.1002 /$ pola.22381

[15] Laita H., Boufi S., Gandini A.: The application of the Diels-Alder reaction to polymers bearing furan moieties. 1. Reactions with maleimides. European Polymer Journal, 33, 1203-1211 (1997).

DOI: 10.1016/S0014-3057(97)00009-8

[16] Loy D. A., Wheeler D. R., McElhanon J. R., Saunders R. S., Durbin-Voss M. L.: Method of making thermally removable polyurethanes. U.S. Patent 6403753, USA (2002).

[17] Bibiao J., Jianjun H., Wenyun W., Luxia J., Xinxian C.: Synthesis and properties of novel polybismaleimide oligomers. European Polymer Journal, 37, 463-470 (2001)

DOI: $10.1016 / \mathrm{S} 0014-3057(00) 00147-6$

[18] Szalai M. L., McGrath D. V., Wheeler D. R., Zifer T., McElhanon J. R.: Dendrimers based on thermally reversible furan-maleimide Diels-Alder adducts. Macromolecules, 40, 818-823 (2007).

DOI: $10.1021 / \mathrm{ma} 062093 \mathrm{w}$

[19] Merve Kose M., Yesilbag G., Sanyal A.: Segment block dendrimers via Diels-Alder cycloaddition. Organic Letters, 10, 2353-2356 (2008). DOI: $10.1021 / \mathrm{ol} 800553 \mathrm{t}$

[20] Vieyres A., Lam T., Gillet R., Franc G., Castonguay A., Kakkar A.: Combined $\mathrm{Cu}^{\mathrm{I}}$-catalysed alkyne-azide cycloaddition and furan-maleimide Diels-Alder 'click' chemistry approach to thermoresponsive dendrimers. Chemical Communications, 46, 1875-1877 (2010). DOI: $10.1039 / B 924888$ A

[21] Polaske N. W., McGrath D. V., McElhanon J. R.: Thermally reversible dendronized linear AB step-polymers via 'click' chemistry. Macromolecules, 44, 3203-3210 (2011). DOI: $10.1021 / \mathrm{ma} 200296 \mathrm{t}$

[22] McElhanon J. R., Russick E. M., Wheeler D. R., Loy D. A., Aubert J. H.: Removable foams based on an epoxy resin incorporating reversible Diels-Alder adducts. Journal of Applied Polymer Science, 85, 1496-1502 (2002).

DOI: $10.1002 / a p p .10753$

[23] Hobbs M. L.: Modeling epoxy foams exposed to firelike heat fluxes. Polymer Degradation and Stability, 89, 353-372 (2005).

DOI: 10.1016/j.polymdegradstab.2005.01.021

[24] Tian Q., Rong M. Z., Zhang M. Q., Yuan Y. C.: Synthesis and characterization of epoxy with improved thermal remendability based on Diels-Alder reaction. Polymer International, 59, 1339-1345 (2010). DOI: $10.1002 /$ pi.2872
[25] Tian Q., Rong M. Z., Zhang M. Q., Yuan Y. C.: Optimization of thermal remendability of epoxy via blending. Polymer, 51, 1779-1785 (2010).

DOI: $10.1016 /$ j.polymer.2010.02.004

[26] Goiti E., Huglin M. B., Rego J. M.: Some properties of networks produced by the Diels-Alder reaction between poly(styrene-co-furfuryl methacrylate) and bismaleimide. European Polymer Journal, 40, 219-226 (2004).

DOI: $10.1016 /$ j.eurpolymj.2003.09.017

[27] Adzima B. J., Aguirre H. A., Kloxin C. J., Scott T. F., Bowman C. N.: Rheological and chemical analysis of reverse gelation in a covalently cross-linked DielsAlder polymer network. Macromolecules, 41, 91129117 (2008).

DOI: $10.1021 / \mathrm{ma} 801863 \mathrm{~d}$

[28] Zhang Y., Broekhuis A. A., Picchioni F.: Thermally self-healing polymeric materials: The next step to recycling thermoset polymers? Macromolecules, 42, 1906-1912 (2009).

DOI: $10.1021 / \mathrm{ma} 8027672$

[29] Kavitha A. A., Singha N. K.: 'Click chemistry' in tailor-made polymethacrylates bearing reactive furfuryl functionality: A new class of self-healing polymeric material. Applied Materials and Interface, 1, 14271436 (2009). DOI: $10.1021 / \mathrm{am} 900124 \mathrm{c}$

[30] Magana S., Zerroukhi A., Jegat C., Mignard N.: Thermally reversible crosslinked polyethylene using DielsAlder reaction in molten state. Reactive and Functional Polymers, 70, 442-448 (2010).

DOI: 10.1016/j.reactfunctpolym.2010.04.007

[31] Imai Y., Itoh H., Naka K., Chujo Y.: Thermally reversible IPN organic-inorganic polymer hybrids utilizing the Diels-Alder reaction. Macromolecules, 33, 4343-4346 (2000).

DOI: $10.1021 / \mathrm{ma} 991899 \mathrm{~b}$

[32] Adachi K., Achimuthu A. K., Chujo Y.: Synthesis of organic-inorganic polymer hybrids controlled by DielsAlder reaction. Macromolecules, 37, 9793-9797 (2004). DOI: $10.1021 / \mathrm{ma} 0400618$

[33] Costanzo P. J., Beyer F. L.: Thermoresponsive, optically active films based on Diels-Alder chemistry. Chemistry of Materials, 19, 6168-6173 (2007). DOI: $10.1021 / \mathrm{cm} 701864 \mathrm{r}$

[34] McElhanon J. R., Zifer T., Kline S. R., Wheeler D. R., Loy D. A., Jamison G. M., Long T. M., Rahimian K., Simmons B. A.: Thermally cleavable surfactants based on furan-maleimide Diels-Alder adducts. Langmuir, 21, 3259-3266 (2005).

DOI: $10.1021 / 1 \mathrm{a} 047074 \mathrm{z}$

[35] Zhu J., Kell A. J., Workentin M. S.: A retro-DielsAlder reaction to uncover maleimide-modified surfaces on monolayer-protected nanoparticles for reversible covalent assembly. Organic Letters, 8, 4993-4996 (2006).

DOI: $10.1021 / 010615937$ 
[36] Gevrek T. N., Ozdeslik R. N., Sahin G. S., Yesilbag G., Mutlu S., Sanyal A.: Functionalization of reactive polymeric coatings via Diels-Alder reaction using microcontact printing. Macromolecular Chemistry and Physics, 213, 166-172 (2012).

DOI: $10.1002 /$ macp.201100406

[37] Liu Y-L., Hsieh C-Y.: Crosslinked epoxy materials exhibiting thermal remendablility and removability from multifunctional maleimide and furan compounds. Journal of Polymer Science Part A: Polymer Chemistry, 44, 905-913 (2006).

DOI: $10.1002 /$ pola.21184

[38] McElhanon J. R., Wheeler D. R.: Thermally responsive dendrons and dendrimers based on reversible furan-maleimide Diels-Alder adducts. Organic Letters, 3, 2681-2683 (2001).

DOI: $10.1021 / 010101281$

[39] Gaina C., Ursache O., Gaina V.: Re-mendable polyurethanes. Polymer-Plastics Technology and Engineering, 50, 712-718 (2011).

DOI: $10.1080 / 03602559.2010 .551392$

[40] Gaina C., Ursache O., Gaina V., Buruiana E., Ionita D.: Investigation on the thermal properties of new thermo-reversible networks based on poly(vinyl furfural) and multifunctional maleimide compounds. Express Polymer Letters, 6, 129-141 (2012). DOI: $10.3144 /$ expresspolymlett.2012.14

[41] Gaina V., Ursache O., Gaina C., Buruiana E.: Novel thermally-reversible epoxy-urethane networks. Designed Monomers and Polymers, 15, 63-73 (2012). DOI: $10.1163 / 156855511 X 606155$

[42] Gaina V., Gaina C.: AB-monomers. I. Synthesis and polymerization of furyl-maleimide monomers. Revue Roumaine de Chimie, 48, 881-890 (2003).

[43] Cristea M., Gaina C., Gheorghiu Ionita D., Gaina V.: Dynamic mechanical analysis on modified bismaleimide resins. Journal of Thermal Analysis and Calorimetry, 93, 69-76 (2008). DOI: $10.1007 / \mathrm{s} 10973-007-8802-4$
[44] Jingwu S., Jitao H., Shixiang S.: The synthesis of polyurethane with (alkylamino)pyridine functions. Journal of Macromolecular Science Part A Pure and Applied Chemistry, 32, 319-322 (1995). DOI: $10.1080 / 10601329508019177$

[45] Goussé C., Gandini A., Hodge P.: Application of the diels-alder reaction to polymers bearing furan moieties. 2. Diels-Alder and retro-Diels-Alder reactions involving furan rings in some styrene copolymers. Macromolecules, 31, 314-321 (1998).

DOI: $10.1021 / \mathrm{ma9710141}$

[46] Zhang J., Goodman I., Fort R. J., Sheldon R. P.: Properties of polyurethane elastomers prepared from 1,1'iso-propylidene bis-(p-phenylene-oxy)di-propanol-2, a polyether (or polyester), and 4,4'-diphenylmethane diisocyanate (MDI) by one-step reaction method. Polymer Communications, 1, 1-10 (1985).

[47] Versteegen R. M., Kleppinger R., Sijbesma R. P., Meijer E. W.: Properties and morphology of segmented copoly(ether urea)s with uniform hard segments. Macromolecules, 39, 772-783 (2006).

DOI: $10.1021 / \mathrm{ma} 051874 \mathrm{e}$

[48] Turri S., Levi M.: Wettability of polyhedral oligomeric silsesquioxane nanostructured polymer surfaces. Macromolecular Rapid Communications, 26, 1233-1236 (2005).

DOI: $10.1002 /$ marc. 200500274

[49] Vlad S., Spiridon I., Grigoraş C. V., Drobota M., Nistor A.: Thermal, mechanical and wettability properties of some branched polyetherurethane elastomers. e-Polymers, no.004 (2009).

[50] Joshi R. G., Goel A., Mannari V. M., Finlay J. A., Callow M. E., Callow J. A.: Evaluating fouling-resistance and fouling-release performance of smart polyurethane surfaces: An outlook for efficient and environmentally benign marine coatings. Journal of Applied Polymer Science, 114, 3693-3703 (2009).

DOI: 10.1002/app.30899 